\title{
IDENTIFICATION AND QUANTIFICATION OF SOME PESTICIDE METABOLITES FROM VEGETABLES BY GC-TOF-MS AND LC-MS-QQQ
}

\author{
ADELA MEGHESAN-BREJA ${ }^{\mathrm{a}, \mathrm{b}}$, CLAUDIA CIMPOIU ${ }^{\mathrm{b}}$, ANAMARIA HOSU $^{\mathrm{b},{ }^{*}}$
}

\begin{abstract}
Considering the international situation regarding the residues of pesticides in vegetables and fruits and the requirement for sensitive and reliable analytical methods that are able to ensure the compliance of marketed food commodities with the law on food safety, the aim of this paper was the identification and determination of some degradation products and metabolites of ten most often used pesticides. Two analytical approaches are proposed and used for the development of reliable screening, quantification and confirmation of pesticides metabolites in different vegetables. The proposed methods have different approaches than the other multi-residue methods for vegetables allowing the extensive investigation of previously undetectable or unknown pesticide metabolites in vegetables. These methods were tested on cherry tomato, cucumber, and chili pepper, some of the most widely consumed vegetables. The results suggests that spraying pesticides in high doses lead to high levels of pesticide residues in the case of some studied vegetables and the concentration of metabolites together concentration of parent pesticide must be taken into account in order to establish the MRL's in vegetables and fruits.
\end{abstract}

Keywords: pesticides metabolites, GC-TOF-MS, LC-MS-QQQ, vegetables

\footnotetext{
${ }^{a}$ Regional Laboratory for Control of Pesticide Residues in Plants and Plant Products, 80 Dezrobirii, str., RO-540243, Targu-Mures, Romania

${ }^{b}$ Babes-Bolyai University, Faculty of Chemistry and Chemical Engineering, 11 Arany Janos, str., RO-400082 Cluj-Napoca, Romania

* Corresponding author ahosu@chem.ubbcluj.ro
} 


\section{INTRODUCTION}

The pesticides are widespread used in modern agriculture leading to the contamination of waters, soil or vegetables. In the European Union (EU) the approval of pesticides and their use are strictly regulated [1, 2], the authorities trying to reduce the number of such permitted products. Any formulated pesticide product includes active ingredients and passive ingredients, the active ingredients being the toxic components. The active ingredients of some pesticides are absorbed by plants and animals and are converted by biotransformation in lethal substances. These substances, known as metabolites, are produced by chemical reactions that naturally occur in the cell metabolism, which in case of vegetables may depend on type of plant, plant vigour and temperature [3, 4]. Also, these metabolites can appear not only in metabolic pathway, but also during the analysis of pesticides as a result of the setting of some instruments parameters. Although these compounds are actually degradation products, in some research papers they have been included in the same category with metabolism metabolites [5-11].

Usually, after separation and identification of compounds by specific analytical methods, especially chromatographic methods, the authentication of metabolites and degradation products is made by isotopic marking. The manufacturer must specify in the safety sheet of each pesticide any confirmed metabolites that may occur, together with the technical characteristics and the metabolic pathway in plants, animals, soil, air, water [4]. However, an important challenge is to detect untargeted compounds and to determine their identity in foods. Therefore, the development of advanced analytical techniques is expected to play a crucial role [12]. Moreover, in order to establish the MRL-s the European Food Safety Authority (EFSA) take into account that no information regarding the storage stability of pesticides, and their metabolism and residues in crops. The MRL of different pesticides are reposted as sum of parent pesticide and its metabolites or isomers. Thus, in the case of no availability of validated analytical methods for degradation products, only the concentration of parent pesticide is reported, those of degradation products being not counted.

Based on the information available on safety sheets and other articles on this topic $[4,5,13-17]$ the most common metabolites and degradation products of ten most used pesticides for plant protection treatments in Romania were selected for development of multi-methods for analysis of various representative matrices. The chosen pesticides were the following: azoxystrobin, iprodione, captan, thiophanate-methyl, carbendazim, folpet, dicofol, dimethoate, fenarimol and bromopropylate.

Considering the international situation regarding the residues of pesticides in vegetables and fruits, the aim of this paper was the identification 
and determination of some degradation products and metabolites of ten most often used pesticides, therewith answering to the important requirements in approaching of exposure to pesticides and health risk. Also, sensitive and reliable analytical methods for the determination of pesticide residues are required to ensure the compliance of marketed food commodities with the law on food safety [18]. The proposed methods allow the extensive investigation of previously undetectable or unknown pesticide metabolites in vegetables. Because only a limited number of these metabolites have been analyzed before and they have a great structural diversity, the general aspects concerning chromatographic separation and the specific conditions for analysis of target compounds were deduced.

The developed methods were tested on cherry tomato, cucumber, and chili pepper, some of the most widely consumed vegetables. Although the crops are suited for pesticide free or organic cultivation efficient and profitable crop protection most often relies on the use of synthetic pesticides [19].

\section{RESULTS AND DISCUSSION}

This study aims to analyse metabolites of various pesticides from quite different classes, namely fungicides, insecticides/acaricides. The used pesticides exert specific effects on all selected vegetables. The studied pesticides and their metabolites have different physical and chemical properties, some of them (i.e. captan, folpet, and dicofol) being a real challenge for any analyst due to their sensitivity to certain $\mathrm{pH}$ and high temperature values. The metabolites are from the so-called "relevant and non-relevant metabolites", relevancy based upon a risk assessment as prescribed in Directive 91/414/EEC [2]. The metabolites of the following pesticides are analysed using either GC-MS or LC-MS techniques.

Captan ((3aR,7aS)-2-[(trichloromethyl) sulfanyl] -3a,4,7,7atetrahydro- $1 H$-isoindole-1,3(2H)-dione) is quickly decomposed in plants, but its fungitoxic activity does not disappear because one of its metabolites seems to have antifungal properties [4]. The main degradation products of captan are tetrahydrophthalimide (THPI) and thiophosgene, which can be identified and quantified by GC. Besides these compounds, due to thermo-sensitivity of captan other degradation products may occur during analysis $[8,9]$. The MRL for captan is reported as sum of captan and THPI quantities. Any validated analytical method does not exist for THPI and analytical standard is commercial available only from 2016.

Dicofol (2,2,2-trichloro-1,1-bis(4-chlorophenyl) ethanol) is an analogue of dichlorodiphenyltrichloroethane (DDT), but the replacing of the hydrogen atom from the first position with a hydroxyl group lead to essential 
changes in chemical properties of the molecule and to the increasing of their volatility. The molecule is quickly degraded under temperature or by hydrolysis, resulting 4,4'-dichlorobenzophenone, the major metabolite of dicofol. This metabolite was identified and quantified in plants by GC-MS [4, 8]. The MRL is reported as sum of isomers.

The main metabolite of folpet ( $N$-(trichloormethylthio) ftalimide), produced in plants as a result of photolysis, is phthalimide, which was identified and determined by GC-MS [4, 8, 9]. The MRL for folpet is given as sum of quantities of folpet and phtalimide, for phtalimide being no analytical standard available on the market.

Iprodione (3-(3,5-dichlorophenyl)-N-isopropyl-2,4-dioxoimidazoli dine1-carboxamide) is stable only at $\mathrm{pH}$ below 5 , being rapidly degraded in aqueous or alcaline solution [7]. Its structure is similar to procymidone and vinclozolin, so it may be metabolized like these pesticides to 3,5dichloroaniline (3,5-DCA), a metabolites that can be determined by GCMS [8]. The MRL for iprodione is given as sum of quantities of iprodion and all its metabolites that contain 3,5-dicloroaniline moiety.

Regarding fenarimol ((RS)-2,4'-dichloro- $\alpha$-(pyrimidin-5-yl) benzhydryl alcohol), the main metabolites identified in vegetables and fruits were dehidroxyfenarimol and 2,4'-dichlorobenzophenone that could be analyzed so far only by LC-MS due to their thermo-sensitivity [10]. In the establishing of MRL only the parent pesticide is taken into account although its degradation product almost always is present with this.

The metabolism pathway of bromopropylate (iso-propyl bis(4bromophenyl)(hydroxy) acetate) in plants shows that it slightly penetrates the leaves or fruit, its identified metabolite being 4,4'-dibromobenzophenone [11]. Only the parent pesticide is taken into account for MRL establishing.

3,4-Dichlophenyl isocyanate is known as metabolite of diuron, but is also used for some pesticide synthesis so that is very likely to be encountered in the analysis of these pesticides.

The most known metabolite of dimethoate (O,O-dimethyl $S$-[2(methylamino)-2-oxoethyl] dithiophosphate) is omethoate (dimethoate Oxon), but on the plant metabolic pathway dimethoate carboxylic acid, omethoate carboxylic acid and des-O-methyl-dimethoate carboxylic acid are also obtained. These metabolites can be analyzed by TLC, HPLC-UV or LC-MS $[4,8]$. The omethoate can be determined by validated analytical methods because it is available as analytical standard and the MRL is reported as the sum of dimethoate and omethoate expressed as dimethoate.

Carbendazim ((methyl 2- benzimidazole carbamate) or MBC) is the primary metabolite of thiophanate-methyl (dimethyl 4,4'-(o-phenylene)bis(3thioallophanate)) whose conversion speed depends on the $\mathrm{pH}$ and 
temperature of environment. This conversion is fast in plants, being catalyzed by sunlight, the metabolism being also accelerated by fungus [4, 9]. Most residual analysis of thiophanate-methyl and carbendazim was done by HPLC-UV, derivated spectrophotometric methods or LC-MS-MS with different pre-treatment of the samples [8]. In the case of some vegetables and fruits the MRL for carbendazim is reported as sum of carbendazim and benomil and in for other vegetables and fruits as sum of carbendazim and thiophanate-methyl, being expressed in both cases as carbendazim.

Azoxystrobin (methyl (2E)-2-(2-\{[6-(2-cyanophenoxy)pyrimidin-4yl]oxy\}phenyl)-3-methoxyacrylate) is degraded both on leaf surface by photolysis and by metabolic pathway of treated plant, resulting compounds that have not toxicological effect and significant antifungal activity At least fifteen metabolites of azoxystrobin were identified in plant, the most important being the azoxystrobin acid and the azoxystrobin metabolite $\mathbf{Z}$ that occur more often in water. Other metabolites, such as metabolite $\mathbf{M}$ (4-(2 cyanophenoxy)6- hydroxypyrimidine), metabolite B (E (2-\{2-[6-(2-cianofenoxi)pirimidin-4iloxi]fenil\}-3-metoxiacrilat), metabolite $\mathbf{D}$ (isomer of metabolite $B$ ), metabolite $\mathbf{F}$ (2- hydroxybenzonitrile) and metabolite L (2-\{2-[6-(2- cyanophenoxy) pyrimidin4-yloxy] phenyl\} glycolic acid) were identified in rice, wheat, grapes and peanuts by TLC, HPLC, LC-MS or GC [6]. The MRL is established using only the parent pesticides, its metabolites being not considered.

\section{The choice of the extraction method}

The extraction of target compounds is the most important step of pesticides residues and metabolites determination. Therefore, the finding an appropriate extraction method which provide an almost "clean" extract that not influence the sensibility and selectivity of determination is absolutely necessary. Also, the extraction method must be able to remove most of the co-extractable compounds and can be applied to wide variety of pesticides [20, 21]. Co-extractable compounds, such as lipids, dyes and non-polar compounds are always present when pesticides are extracted from vegetables. The presence of these compounds cause different problems in the further analysis, including the emulsifying, turbidity, the contamination of devices and, the most important one being the masking of the target compounds. Commonly, the co-extractable compounds are removed from the extract by different methods.

The extraction method is chosen on the basis of the recoveries obtained on a control spiked samples (Table 1). The values of recoveries are statistically compared (t-test for pair values) using GraphPad InStat statistical program. 
Table 1. Recovery rates of pesticides and their metabolites in spiked samples

\begin{tabular}{|c|c|c|c|c|c|c|}
\hline & \multicolumn{6}{|c|}{ Recovery rate (\%) } \\
\hline $\begin{array}{c}\text { Vegetables } \\
\begin{array}{c}\text { Extraction method } \\
\text { Pesticide }\end{array}\end{array}$ & $\begin{array}{c}\text { QuEChERS } \\
\text { modified }\end{array}$ & $\begin{array}{c}\text { Mini-Luke } \\
\text { modified }\end{array}$ & $\begin{array}{c}\text { QuEChERS } \\
\text { modified }\end{array}$ & $\begin{array}{c}\text { Mini-Luke } \\
\text { modified }\end{array}$ & $\begin{array}{c}\text { QuEChERS } \\
\text { modified }\end{array}$ & $\begin{array}{c}\text { Mini-Luke } \\
\text { modified }\end{array}$ \\
\hline $\begin{array}{c}\text { Tetrahydro- } \\
\text { phthalimide }\end{array}$ & 45 & 60 & 47 & 57 & 64 & 72 \\
\hline Thiophosgene & 32 & 99 & 30 & 102 & 34 & 106 \\
\hline $\begin{array}{c}4,4^{\prime}-\text {-Dichloro- } \\
\text { benzophenone }\end{array}$ & 74 & 44 & 113 & 42 & 92 & 40 \\
\hline Phthalimide & 57 & 70 & 41 & 73 & 54 & 62 \\
\hline $\begin{array}{c}2,4 \\
\text { benzophenone }\end{array}$ & 66 & 58 & 69 & 59 & 67 & 56 \\
\hline Omethoate & 75 & 82 & 35 & 60 & 20 & 39 \\
\hline Carbendazim & 74 & 136 & 50 & 100 & 78 & 154 \\
\hline Azoxystrobin acid & 75 & 103 & 75 & 85 & 116 & 83 \\
\hline
\end{tabular}

\section{Modified QueChERS extraction method}

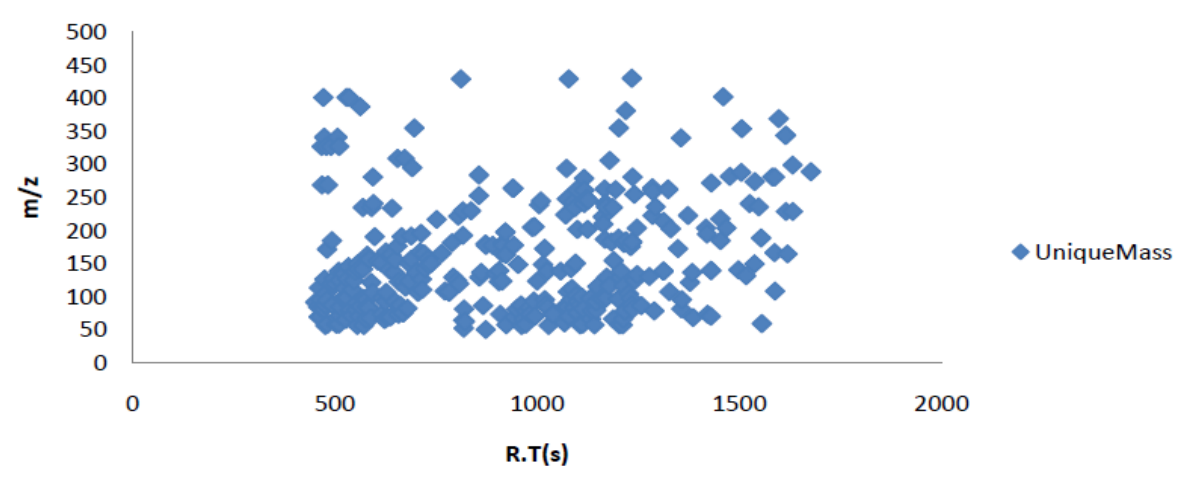

MiniLuke modified extraction method

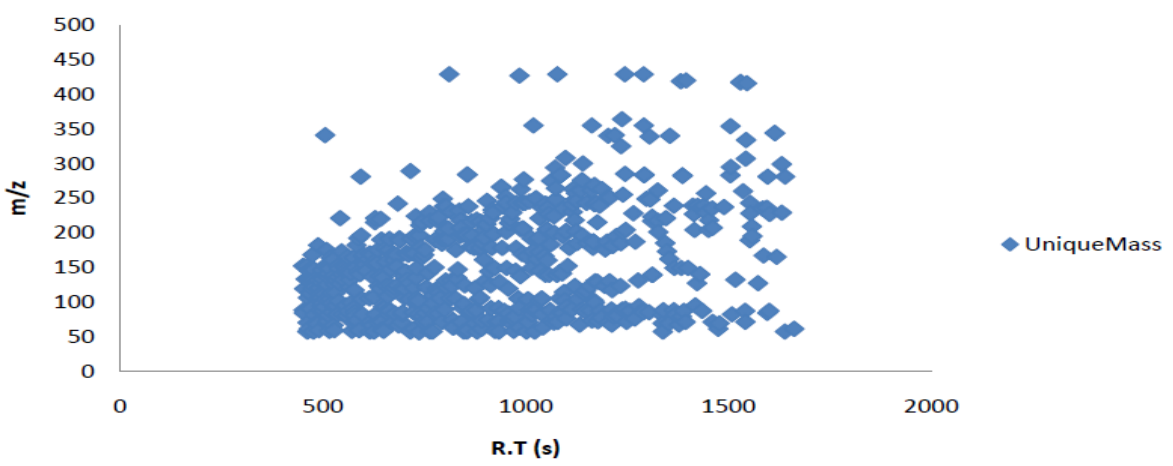

Figure 1. Co-extractive compounds found in the cucumber extracts 
Also, the LOQ values and the chromatographic peak shapes are taken into account for certain decisions. The main goal is to provide adequate and reproducible recovery rates for analyzed metabolites and to improve the extraction and stability of challenging compounds. Moreover, the presence of co-extractable compounds must be taken into account because lot of them may appear in the extracts obtained after both methods (e.g. Figure 1).

Thus, modified QuEChERS method gives higher recoveries than modified MINILUKE method in the case of 4,4'-dichlorobenzophenone and azoxystrobin acid, while for thiophosgene and phthalimide the most efficient extraction method has been found to be the modified MINILUKE. In some cases (e.g. tetrahydrophthalimide and omethoate) both method give comparable recovery rates for all spiked samples and the characteristics of chromatographic peaks are taken into account for choosing the appropriate extraction method. In these cases the modified QuEChERS method is preferable to be used because the chromatographic peaks are well resolved and the matrix background is almost non-existent (Figure 2). For 2,4dichlorobenzophenone both methods give similar results in terms of recovery rate and peak shapes. Unlike these metabolites, the 4,4'dibrombenzophenone and 3,4-dichlorophenyl isocyanate can be extracted only by modified MINILUKE method and for 3,5-dichloroaniline merely buffered QUECHERS method has been proven to be effective. These three compounds do not appear in the resulting extract, being extractable only by specified method. Regarding carbendazim, the buffered QUECHERS method is preferred although the MINILUKE method provides better results, but that can be influenced by co-extractable compounds, especially chlorophyll.

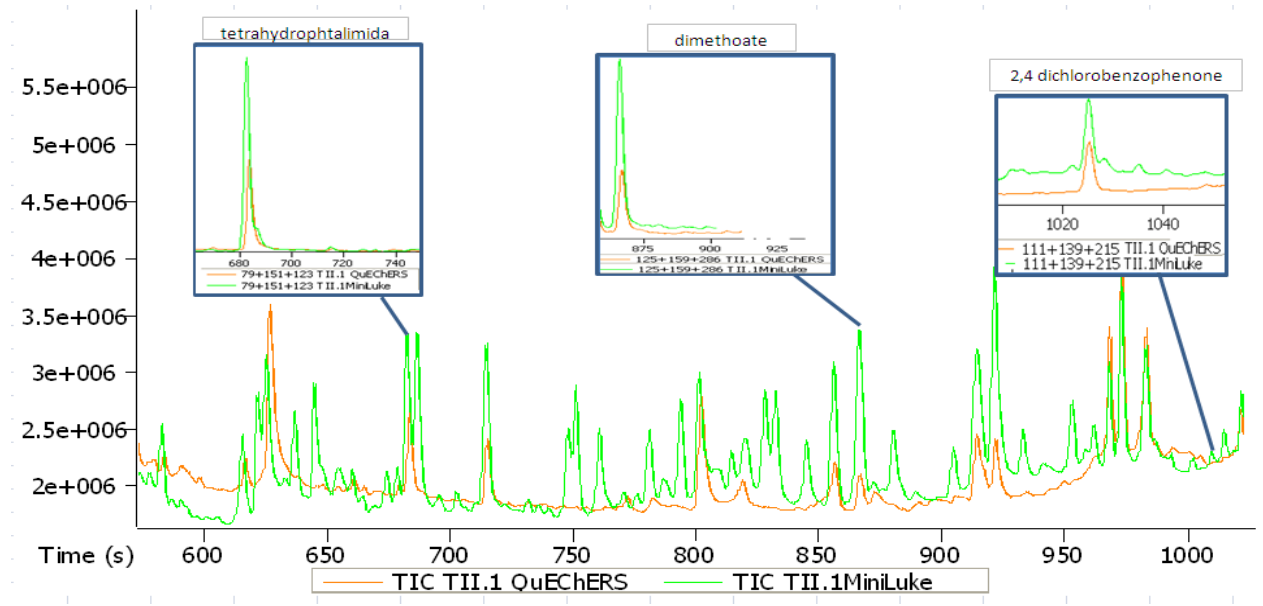

Figure 2. GC separation of pesticides standards 


\section{GC-TOF-MS analysis}

The metabolites analyzed by GC-TOF-MS are the following: tetrahydrophthalimide, thiophosgene, 4,4'-dichlorobenzophenone, phthalimide, 3,5-dichloroaniline, 4,4'-dibrombenzophenone, 2,4-dichlorobenzophenone and 3,4-dichlophenyl isocyanate. These metabolites are the most important as a result of the metabolic pathways of tested pesticides. The GC separation also shows other degradation products, but their similarities with mass spectra from libraries were below the relevant limit values imposed by the regulations in force.

The GC-TOF-MS assay is performed using the previously developed and validated method for 85 pesticides analysis from various fruits and vegetables, including the parent pesticides of the target metabolites [22]. Each compound is identified and quantified using the retention times, by monitoring three selected $\mathrm{m} / \mathrm{z}$ ions (Table 2) and by comparing registered mass spectra with those from ten spectra libraries (overlap of at least $70 \%$ ).

Table 2. The analyzed metabolites, retention time (RT), and specific ions/MRM transitions used for quantification $(\mathrm{m} / \mathrm{z})$

\begin{tabular}{|c|c|c|c|}
\hline Technique & Metabolite & $\begin{array}{c}\text { Retention } \\
\text { time }(\mathbf{s})\end{array}$ & Ions $(\boldsymbol{m} / \mathbf{z}) /$ Transitions \\
\hline GC-TOF-MS & Tetrahydrophthalimide & 634.98 & $79,123,151$ \\
\cline { 2 - 4 } & Thiophosgene & 953.00 & 79,114 \\
\cline { 2 - 4 } & 4,4 '-Dichlorobenzophenone & 881.88 & $75,111,139$ \\
\cline { 2 - 4 } & Phthalimide & 668.63 & $76,104,147$ \\
\cline { 2 - 4 } & 3,5-Dichloroaniline & 464.38 & 121,161 \\
\cline { 2 - 4 } & 4,4'-Dibrombenzophenone & 1024.50 & $76,183,340$ \\
\cline { 2 - 4 } & 2,4-Dichlorobenzophenone & 821.75 & $75,111,139$ \\
\cline { 2 - 4 } & 3,4-Dichlorophenylisocyanate & 390.13 & $113,159,187$ \\
\hline \multirow{4}{*}{ LC-MS-QQQ } & Omethoate & 60.60 & $214 \rightarrow 125,214 \rightarrow 183$ \\
\cline { 2 - 4 } & Carbendazim & 66.00 & $192 \rightarrow 160,192 \rightarrow 132$ \\
\cline { 2 - 4 } & Azoxystrobin acid & 1041.00 & $404 \rightarrow 372,404 \rightarrow 344$ \\
\hline
\end{tabular}

Tetrahydrophthalimide is the most important metabolite of captan and occurs due to thermal degradation of the parent pesticide that is also favored by the increasing temperature in $\mathrm{GC}$ analysis and by the $\mathrm{pH}$ of analyzed extract. Thiophosgene is a metabolite of captan too, but not so well known and analyzed as tetrahydrophthalimide. Unfortunately, for these metabolites has not been regulated as residues in vegetables and fruits, none Maximum Residue Limits (MRL) being specified. The 4,4'dichlorobenzophenone, primary metabolite of dicofol, can be identified and quantified only by GC. This compound appears in all GC analysis of dicofol together with its isomer 2,4'-dichlorobenzophenone, which is the main 
metabolite of fenarimol as well. Phthalimide is the most important metabolite of folpet and, as in the case of metabolites of captan, it appears in the GC analysis of the parent active substance. In the last years a growing interest is dedicated to this degradation product of captan. International regulations do not assign any MRL for phthalimide and, moreover, this metabolite is not included in the maximum permissible limit of folpet as its degradation product. Nevertheless, in the reports for European Food Safety Authority (EFSA) these compounds must be mentioned as metabolites of the parent pesticides. The 3,5-dichloroaniline is the main metabolite of iprodione, occurring also as a degradation product of vinclozolin and procymidone. Recently, this compound is used as a biomarker of iprodione and vinclozolin in human urine [23], thus the possibility to be included on the regulations of pesticides in vegetables in the near future is forthcoming. The 2,4dichlorobenzophenone is the main metabolite of fenarimol and a secondary metabolite of dicofol, but it is not always identified from samples in which one of parent pesticide are determined. Literature indicates [24] that 3,4dichlorophenylisocyanate is the metabolite of diuron, but this compound is also used as an intermediate substance for the pesticides manufacture, so is difficult to determine with accuracy its provenance.

\section{LC-MS-QQQ analysis}

Nowadays, a high-performance liquid chromatography coupled with a QQQ tandem mass spectrometer, working in the multiple reaction monitoring (MRM) mode, is the most frequently platform used in the analysis of pesticide residues in food [18].

The following metabolites are analyzed by LC-MS-QQQ: omethoate, carbendazim and azoxystrobin acid. The target compounds are identified and quantified on the basis of retention time and two Multiple Reaction Monitoring (MRM) transitions (Table 2). The target metabolites cannot be analysed by GC-TOF-MS.

Omethoate is the main and most common metabolite of dimethoate. Although the dimethoate can be successfully quantified by GC-TOF-MS, its metabolite, omethoate, cannot be easily analyzed by same technique and its identification can be made only at certain concentration levels. The carbendazim, a pesticid that is not approved for vegetables, is at the same time a metabolite or degradation product of thiophanate methyl and benomyl, two pesticides often used for the vegetables protection treatments. Carbendazim, a very polar compound determined only by LC $[8,13]$, could generate some problems in the multiresidue analysis on reverse phase. The azoxystrobin acid occurs by degradation of azoxystrobin, being his major identified metabolite. 


\section{Determination of metabolites in real samples}

For testing the applicability of the developed multiresidues methods to a variety of vegetable matrices, three different vegetables from "high content water" commodity of food were selected: cherry tomato, cucumber, and chili pepper.

The quantification of metabolites on samples was done on the basis of calibration curves that are presented in Table 3. The compounds that do not fulfill the criteria of quantification are declared "only identified". The results were expressed as $\mathrm{mg}$ of pesticide/kg of vegetable.

Tetrahydrophthalimide is identified in cherry tomatoes, cucumber and chili peppers, the overlapping of the obtained spectrum with that of library being $83.7 \%, 95.1 \%$ and $91.4 \%$ respectively.

Table 3. The obtained quantities of target compounds found in the analyzed real samples $(\mathrm{mg} / \mathrm{kg})$

\begin{tabular}{|c|c|c|c|c|c|c|c|c|c|c|c|c|c|c|}
\hline \multirow[t]{3}{*}{ Metabolite } & \multirow{3}{*}{$\begin{array}{c}\text { Calibration } \\
\text { curve }\end{array}$} & \multirow[t]{3}{*}{$r$} & \multicolumn{4}{|c|}{ Cherry tomatoes } & \multicolumn{4}{|c|}{ Cucumbers } & \multicolumn{4}{|c|}{ Chili peppers } \\
\hline & & & \multicolumn{2}{|c|}{ T1 } & \multicolumn{2}{|c|}{ T2 } & \multicolumn{2}{|c|}{ T1 } & \multicolumn{2}{|c|}{ T2 } & \multicolumn{2}{|c|}{$\mathrm{T} 1$} & \multicolumn{2}{|c|}{ T2 } \\
\hline & & & $3 d$ & $10 d$ & 3d & 10d & 3d & $10 d$ & 3d & $10 d$ & 3d & $10 d$ & 3d & $10 d$ \\
\hline $\begin{array}{c}\text { Tetrahydroph } \\
\text { thalimide }\end{array}$ & $\begin{array}{c}\mathrm{y}=776.042 \mathrm{x}- \\
7642.850\end{array}$ & 0.9974 & 0.558 & 0.286 & 0.283 & 0.168 & 0.319 & 0.138 & 1.741 & 1.140 & 1.988 & 1.061 & 1.915 & 0.172 \\
\hline Thiophosgene & $\begin{array}{c}y=65.340 x- \\
1841.630\end{array}$ & 0.9959 & 0.521 & 0.181 & 2.089 & \begin{tabular}{|l|}
1.330 \\
\end{tabular} & 2.161 & 0.966 & 1.127 & 0.309 & 0.272 & - & 0.335 & - \\
\hline $\begin{array}{c}4,4^{\prime}- \\
\text { Dichloroben } \\
\text { zophenone }\end{array}$ & $\begin{array}{c}y=453.338 x \\
+624.167\end{array}$ & 0.9971 & 0.127 & 0.060 & 0.196 & 0.068 & 0.425 & 0.250 & 0.317 & 0.103 & 0.208 & 0.088 & 0.310 & 0.065 \\
\hline Phthalimide & $\begin{array}{c}y=874.344 x- \\
30363.200\end{array}$ & 0.9961 & 3.569 & 1.823 & 1.937 & \begin{tabular}{|l|}
1.200 \\
\end{tabular} & 5.168 & 1.450 & 1.509 & 0.812 & 4.833 & 1.163 & 4.670 & 1.110 \\
\hline $\begin{array}{c}3,5- \\
\text { Dichloroaniline }\end{array}$ & $\begin{array}{c}\text { Only } \\
\text { identified }\end{array}$ & - & yes & yes & yes & yes & - & - & - & - & - & - & - & - \\
\hline $\begin{array}{c}4,4^{\prime}- \\
\text { Dibromoben } \\
\text { zophenone }\end{array}$ & $\begin{array}{c}\text { Only } \\
\text { identified }\end{array}$ & - & yes & yes & yes & yes & - & - & - & - & - & - & - & - \\
\hline $\begin{array}{c}2,4- \\
\text { Dichloroben } \\
\text { zophenone }\end{array}$ & $\begin{array}{c}\text { Only } \\
\text { identified }\end{array}$ & - & yes & yes & yes & yes & - & - & - & - & yes & yes & yes & yes \\
\hline $\begin{array}{c}\text { 3,4- } \\
\text { Dichlorophen } \\
\text { ylisocyanate }\end{array}$ & $\begin{array}{c}\text { Only } \\
\text { identified }\end{array}$ & - & yes & yes & yes & yes & - & - & - & - & - & - & - & - \\
\hline Omethoate & $\begin{array}{c}y=650.488 x \\
+805.569\end{array}$ & 0.9987 & $<\mathrm{LOQ}$ & $<\mathrm{LOQ}$ & $<\mathrm{LOQ}$ & $<\mathrm{LOQ}$ & 0.057 & 0.013 & 0.068 & 0.011 & 0.040 & 0.020 & 0.032 & 0.038 \\
\hline Carbendazim & $\begin{array}{c}y=333.652 x \\
+1573.087\end{array}$ & 0.9972 & $<\mathrm{LOQ}$ & $<\mathrm{LOQ}$ & $<\mathrm{LOQ}$ & $<\mathrm{LOQ}$ & 0.020 & 0.000 & 0.040 & 0.000 & 0.090 & 0.060 & 0.080 & 0.060 \\
\hline $\begin{array}{l}\text { Azoxystrobin } \\
\text { acid }\end{array}$ & $\begin{array}{c}\text { Only } \\
\text { identified }\end{array}$ & - & yes & yes & yes & yes & yes & - & - & - & yes & - & - & - \\
\hline
\end{tabular}

The degradation of captan is fast being facilitated by humidity and moderate temperature of soil and air. This can explain the higher concentrations of tetrahydrophthalimide, especially in chili peppers.

In this study, thiophosgene was identified and subsequently quantified in cherry tomatoes, cucumber and chili peppers $(91.0 \%, 87.2 \%$ 
and $90.4 \%$ overlap of the spectra). It must be mention that this metabolite disappears from chili pepper after 10 days.

It is interesting to compare the degradation of pesticide and its metabolites. For example, Figure 3 represented the degradation curves of captan, tetrahydrophthalimide and thiophosgene, where it can be seen that thiophosgene tends to accumulate much more than the other metabolite from one treatment to another. This trend was not maintained in the case of cucumbers, concentration of tetrahydrophthalimide being higher than the thiophosgene. In chili peppers, it seems that the metabolism and elimination is rapid, so that after 10 days the parent pesticide and its metabolites are not present in the sample.

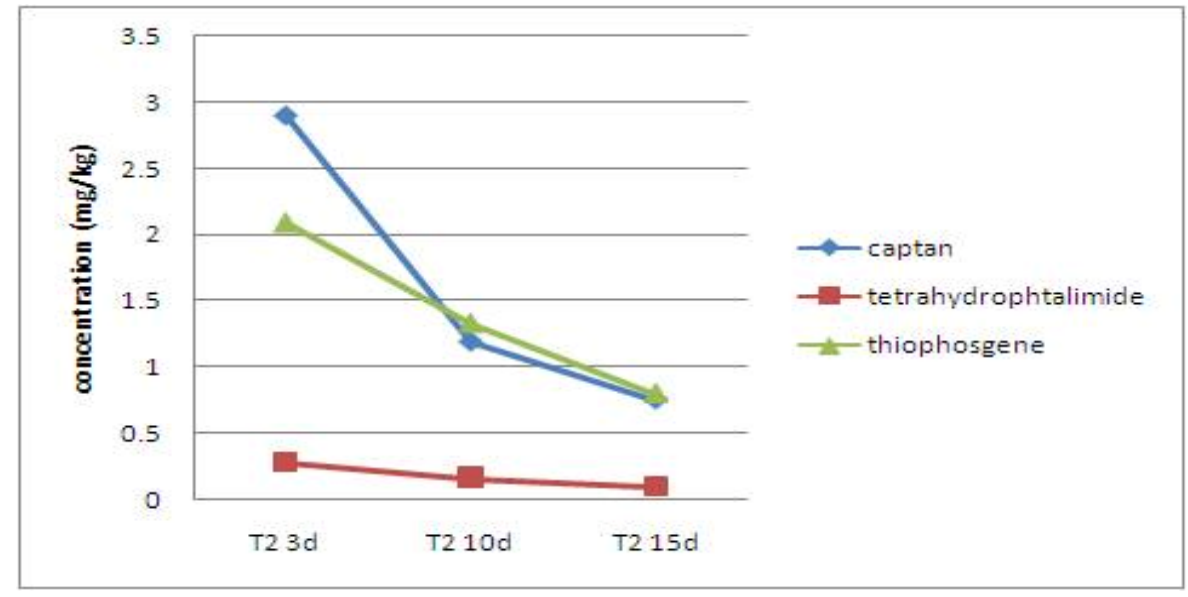

Figure 3. The degradation curves of captan, tetrahydrophthalimide and thiophosgene

The 4,4'-dichlorobenzophenone is determined in cherry tomatoes, cucumber and chili peppers, the spectra similarities being between $87.7 \%$ and $96.6 \%$. The concentrations of $4,4^{\prime}$-dichlorobenzophenone are much smaller than those of dicofol proving once again the persistence of this pesticide.

The phthalimide is determined in all analyzed real samples with probability of $80.9 \%-97.3 \%$. The degradation shows the same descending trend as pesticide whose metabolite is and is more rapid in cucumbers and chili peppers than in cherry tomatoes. The most important factors that influence its determination can be the organic extract composition and the $\mathrm{pH}$ value.

The 3,5-dichloroaniline, 4,4'-dibromobenzophenone and 3,4dichlorophenylisocyanate are identified by proposed GC method only in cherry tomatoes. This fact is probably due to the more acidic $\mathrm{pH}$ of cherry 
tomatoes and/or to the different metabolic pathway of parent pesticides in the studied vegetables. According to the Center for Food Safety and Applied Nutrition at the U.S. Food and Drug Administration, the $\mathrm{pH}$ of fresh vegetables is into the range of 4.3-4.9 for tomatoes, 5.1-5.7 for cucumbers and $4.9-6.1$ for chili peppers.

The 2,4-dichlorobenzophenone is identified in cherry tomatoes and chili peppers with a probability of $85.1 \%$.

Omethoate is determined only in cucumbers and chili pepper, while in cherry tomatoes being below LOQ.

Carbendazim as metabolite, is determined in the cucumbers and the chili peppers, but its degradation is more accelerated in cucumbers being absent after ten days from both treatments. The situation of carbendazim in chili pepper must be mention. It is well known that the LMA for thiophanate-methyl is expressed as sum of thiophanate-methyl and carbendazim, while in the EFSA reports the carbendazim can be reported as stand-alone substance. The LMA is $0.1 \mathrm{mg} / \mathrm{kg}$ after the release time of 3 days. The experimental value obtained after three days subsequent to treatment II is below LMA $(0.08<0.1)$, but if the quantity of thiophanate-methyl is taken into consideration, the resulted value exceed LMA $(0.136>0.1)$.

As in the situation of omethoate, the residue of this metabolite within the cherry tomatoes is minor being below LOQ.

Azoxystrobin acid is identified in all real samples, but unlike cherry tomatoes, in which is present in all samples, in the cucumbers and the chili peppers is identified only in the samples taken after three days from treatment. This fact leads us to conclude that the azoxystrobin acid is rapidly eliminated from cucumbers and chili peppers.

Concluding, in the cherry tomatoes six metabolites can be quantified, but all of them are below LMA values. Besides these, other five metabolites are identified. In the case of the cucumbers, six metabolites are quantified, all being below LMA, and another one metabolite is only identified. Regarding chili pepper, six pesticides have been determined and two other metabolites have been only identified. The concentration of metabolites in studied vegetables is lower than that is considered safe.

\section{CONCLUSIONS}

Two analytical approaches are used for the development of reliable screening, quantification and confirmation of pesticides metabolites in different vegetables. The proposed methods have different approaches than the other multi-residue methods for vegetables. A combination between proper extraction method and gas and liquid chromatography coupled with 
mass spectrometry detection ensure a quick, cheap, effective, rugged, and safe multi-residue method for the analysis of pesticide metabolites.

The results suggests that spraying pesticides in high doses lead to high levels of pesticide residues in the case of some studied vegetables and should be discouraged because it may facilitate the emergence of various diseases.

The results suggest that the concentration of metabolites together concentration of parent pesticide must be taken into account in order to establish the LMA in vegetables and fruits.

\section{EXPERIMENTAL SECTION}

\section{Materials and reagents}

The cherry tomatoes, cucumbers and chili pepper were selected as representative matrices. The vegetables used in this study were grown in our garden. Two treatments for plant protection with solution of chosen pesticides were applied when the fruits of vegetables were grown at a rate of $10 \%$. The solutions of each pesticide were prepared according to the instructions given by manufacturers for each type of plant culture. The plants were treated with pesticides by spraying with a hand pump dispenser just as the practice of small producers. The time between treatments was twenty days and the samples were taken after three and ten after each treatment. The sampling times were chosen according to the release time of tested pesticides.

All pesticides standards were of analytical grade and were purchased from Sigma-Aldrich (Munich, Germany). The stock solution of standards $(1000 \mu \mathrm{g} / \mathrm{mL}$ of each pesticide) was prepared in toluene for GC analysis and in acetonitrile for LC analysis and was stored at $-18^{\circ} \mathrm{C}$. A standards solution of intermediary concentration $(5 \mu \mathrm{g} / \mathrm{mL})$ and the working standards solutions were prepared by dilution of stock solutions with isooctane - toluene, 9:1 (v/v) for GC analysis and with acetonitrile - water, 1:1 $(\mathrm{v} / \mathrm{v})$ for LC analysis. Solution of hexachlorobenzene (HCB) $(0.2 \mu \mathrm{g} / \mathrm{mL})$ was prepared in iso-octane - toluene, 9:1 (v/v) and was used as internal standard (IS) for GC-MS analysis. In the case of LC-MS analysis no internal standard was used.

GC calibration curves were constructed at seven levels of concentration, namely 0.01-0.03-0.06-0.09-0.27-0.54-0.81 $\mu \mathrm{g} / \mathrm{mL}$ and LC calibration curves were made at five levels of calibration between 0.01 and $0.4 \mu \mathrm{g} / \mathrm{mL}$. The calibrations were made on equally standard solutions and fortified samples (cherry tomatoes, cucumber and peppers) subjected to both extraction methods. 
All solvents of analytical grade (acetonitrile, acetone, dichloromethane, petroleum ether, methanol, toluene, iso-octane, acetic acid, formic acid) and anhydrous magnesium sulphate, sodium chloride, sodium acetate were purchased from Sigma-Aldrich (Munich, Germany). Primary-secondary amine (PSA) and PSA dispersive SPE Clean-up tubes (dSPE) were purchased from Supelco, USA and $0.2 \mu \mathrm{m}$ RC filters were purchased from Whatman, Germany.

\section{Sample preparation}

\section{Modified MINILUKE method}

Into a $150 \mathrm{~mL}$ polypropylene centrifuge tube, $10 \mathrm{~mL}$ acetone, $10 \mathrm{~mL}$ dichloromethane and $10 \mathrm{~mL}$ petroleum ether were added to $10 \mathrm{~g}$ of each sample accurately weighted. The sample was extracted for $2 \mathrm{~min}$ at $15.000 \mathrm{rpm}$ using an Ultraturax homogenizer and then it was centrifuged for $5 \mathrm{~min}$ at 4000rpm. The entire upper organic phase was evaporated near to dryness on vacuum evaporator at $40^{\circ} \mathrm{C}$. The residue was re-dissolved in $2 \mathrm{~mL}$ iso-octane toluene, 9:1 (v/v) together with HCB $(0.2 \mu \mathrm{g} / \mathrm{mL})$ and analyzed by GC-TOF/MS after filtered through RC $0.2 \mu \mathrm{m}$. In the case of LC- MS/MS method, the residue obtained after evaporation procedure was re-dissolved in $2 \mathrm{~mL}$ acetonitrile - water, $1: 1(\mathrm{v} / \mathrm{v})$ and filtered through RC $0.2 \mu \mathrm{m}$ before analysis.

\section{Buffered QUECHERS method}

Into a $100 \mathrm{~mL}$ polypropylene centrifuge tube, $10 \mathrm{~mL}$ acetonitrile acidified with $1 \%$ acetic acid was added to $10 \mathrm{~g}$ of each sample. In the case of GC analysis $200 \mu \mathrm{L}$ of $\mathrm{HCB}$ solution $(10 \mu \mathrm{g} / \mathrm{mL})$ was also added as internal standard. To the extracted sample obtained using an Ultraturax homogenizer (15.000rpm for $1 \mathrm{~min}$ ), $4 \mathrm{~g} \mathrm{MgSO}_{4}, 1 \mathrm{~g} \mathrm{NaCl}$ and $1 \mathrm{~g} \mathrm{CH}_{3} \mathrm{COONa}$ were added. Then, the resulting mixture was shaken for $1 \mathrm{~min}$ and centrifuged for $5 \mathrm{~min}$ at 4000rpm. An aliquot of $6 \mathrm{~mL}$ extract was transfer into a $20 \mathrm{~mL}$ PSA cartrige tube which $150 \mathrm{mg}$ PSA and $900 \mathrm{mg} \mathrm{MgSO}_{4}$ were previously added. The resulting mixture was shacked for few seconds, centrifuged for $5 \mathrm{~min}$ at $4000 \mathrm{rpm}$ and then $1 \mathrm{~mL}$ of extract was evaporated under $\mathrm{N}_{2}$ steam. The obtained residue was re-dissolved in iso-octane - toluene, 9:1 (v/v) for GC-TOF/MS analysis and in $1 \mathrm{~mL}$ acetonitrile - water, 1:1 (v/v) for LC analysis. In both cases the redissolved residues were filtered through $\mathrm{RC} 0.2 \mu \mathrm{m}$ before analysis.

\section{Chromatographic analysis}

GC-TOF-MS

An Agilent 6890 series gas chromatograph with two ovens, Agilent 7683 series Autosampler and a split/splitless capillary injector port equipped 
with a LECO Pegasus Time-of-Flight Mass Spectrometer (TOF-MS) (USA) was used for GC-MS analysis. Chromatographic separation was achieved on two capillary columns, first RXi-MS $30 \mathrm{~m} \times 0.25 \mathrm{~mm} \times 0.25 \mu \mathrm{m}$ (Restek,

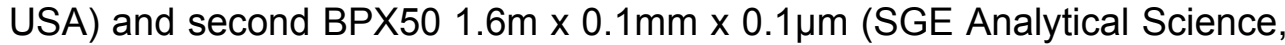
Australia). The injector temperature was $250^{\circ} \mathrm{C}$ and splitless injection was performed using helium as carrier gas with a flow rate of $1.2 \mathrm{~mL} / \mathrm{min}$. The ovens temperatures were programmed without modulation as follow: oven $1-80^{\circ} \mathrm{C}$ initial temperature for $2 \mathrm{~min}$, increasing rate of $20^{\circ} \mathrm{C} / \mathrm{min}$ to $180^{\circ} \mathrm{C}$, $5^{\circ} \mathrm{C} / \mathrm{min}$ to $220^{\circ} \mathrm{C}, 25^{\circ} \mathrm{C} / \mathrm{min}$ to $300^{\circ} \mathrm{C}$ where is held for $10 \mathrm{~min}$; oven 2$110^{\circ} \mathrm{C}$ initial temperature for $2 \mathrm{~min}, 20^{\circ} \mathrm{C} / \mathrm{min}$ to $210^{\circ} \mathrm{C}, 5^{\circ} \mathrm{C} / \mathrm{min}$ to $250^{\circ} \mathrm{C}$, $25^{\circ} \mathrm{C} / \mathrm{min}$ to $330^{\circ} \mathrm{C}$ and held at this temperature for $10 \mathrm{~min}$. The injection volume was $1 \mu \mathrm{L}$. The mass spectrometer was operated in electron ionization mode (EI) and full scan mode monitoring between $\mathrm{m} / \mathrm{z} 40$ and $\mathrm{m} / \mathrm{z} 450$, with ionization energy of $70 \mathrm{eV}$ and acquisition rate of 10 spectra/second. The transfer line temperature was kept at $280^{\circ} \mathrm{C}$.

\section{$L C-M S-Q Q Q$}

For LC-MS analysis, an AGILENT liquid chromatograph equipped with a quaternary pump model 1200 , autosampler and a mass spectrometer triple quadrupole AGILENT 6410A, ionization source type Multi mode ionization (MMI), with electrospray ionization (ESI) in the positive mode were used.

Separation was performed at $25^{\circ} \mathrm{C}$ on a Zorbax Eclipse XDB-C18, $1.8 \mu \mathrm{m}, 4.6 \times 50 \mathrm{~mm}$ column (Agilent). $10 \mu \mathrm{L}$ of sample was injected and the mobile phases consisting of $0.1 \%$ formic acid in water $(A)$ and acetonitrile (B) with a flow rate of $0.4 \mathrm{~mL} / \mathrm{min}$ were used. The elution gradient was: $20-$ $80 \% \mathrm{~B}$ at $0-28 \mathrm{~min}, 80-100 \% \mathrm{~B}$ at $28-30 \mathrm{~min}$, kept this for $1 \mathrm{~min}, 100-20 \% \mathrm{~B}$ at $31-33 \mathrm{~min}$ and then kept $20 \% \mathrm{~B}$ for $2 \mathrm{~min}$. The fragmentation energy and the collision energy were between $70-120 \mathrm{~V}$ and $5-20 \mathrm{eV}$, respectively, being specific of each pesticide. Working parameters were set as follow: capillary voltage $2500 \mathrm{~V}$, the temperature of the gas in the ion source $350^{\circ} \mathrm{C}$, the nebulizer pressure $60 \mathrm{psi}$ and the drying gas flow $5 \mathrm{~L} / \mathrm{min}$. Nitrogen was used as nebulization, desolvation and collision gas.

\section{REFERENCES}

1. European Commission, Off. J. L 230 (1) EU (1991) Council Directive (EEC) No 414/1991 of 15 July 1991 concerning the placing of plant protection products on the market Off $\mathrm{J} L 230,19 / 08 / 1991$.

2. European Union, Off. J. L 309 (1), 2009. 
3. European Commission, Health and Consumers Directorate-General, Regulation (EC) No 1107/2009 concerning the placing of plant protection product on the market.

4. http://www.inchem.org/

5. J. J. Menn, Environmental Health Perspectives, 1978, 27, 113.

6. S. Klimmek, Analytical Method Development and Validation of the DFG Method S19 for the Determination of Residues of Azoxystrobin and the Metabolite R230310 in Plant Matrices. Chemische und Biologische Laboratorien AG, 2004.

7. O. Belafdal, M. Bergon, J. P. Calmon, Pesticide Science, 1986, 17, 335.

8. T. R. Roberts, D. H. Hutson, P. W. Lee, P. H. Nicholls, J. R. Plimmer, "Metabolic Pathways of Agrochemicals: Part 2, Insecticides and fungicides", The Royal Society of Chemistry, Cambridge, 1999.

9. A. Hiroyasu, "Metabolic Maps of Pesticides (Ecotoxicology and Environmental Quality Series)", Academic Press, Inc., 1982.

10. European Commision Directorate D, Food Safety: production and distribution chain, D3 - Chemicals, Contaminants and Pesticides, Review report for the active substance fenarimol, 2007.

11. E. Corta, A. Bakkali, A. Barranco, L. A. Berrueta, B. Gallo, F. Vicente, S. Bogdanov, Talanta, 2000, 52, 169.

12. A. Cifuentes, ISRN Analytical Chemistry, 2012, 2012, 1.

13. L. L. van Eerd, R. E. Hoagland, J. C. Hall, Weed Science, 2003, 51, 472.

14. R. Schöning, R. Schmuck, Bulletin of Insectology, 2003, 56, 41.

15. Conclusion on the peer review of the pesticide risk assessment of the active substance myclobutanil, EFSA Journal, 2010, 8, 1682.

16. A. Vanni, L. Anfossi, A. Cignetti, A. Baglieri, M. Gennari, Journal of Environmental Science and Health, Part B, 2006, 41, 67.

17. World Health Organization, The Joint FAO/WHO Meeting on Pesticide residues in food 2011, FAO (Ed.), Rome, 2012.

18. A. Stachniuk, E. Fornal, Food Analytical Methods, 2016, 9, 1654.

19. S. Walorczyk, I. Kopeć, E. Szpyrka, Food Analytical Methods, 2016, 9, 1155.

20. J. L. Tadeo, "Analysis of Pesticides in Food and Environmental Samples", CRC Press, Taylor \& Francis Group, Boca Raton, 2008. chapter 6.

21. M. Stoytcheva, "Pesticides - Strategies for Pesticides Analysis", InTech, Rijeka, 2011, chapter 8.

22. A. Meghesan-Breja, C. Cimpoiu, A. Hosu, Acta Chromatographica, 2015, 27, 657.

23. C. H. Lindh, M. Littorin, A. Amilon, B. A. Jönsson, Rapid Communication in Mass Spectrometry, 2007, 21, 536.

24. C. Ciscato, C. Barbosa, A. Gebara, "Analysis of Pesticide Residues in Mango by GC/MS/MS With Bond Elut QuEChERS EN Kits - Application Note", Agilent Technologies, Inc., 2015. 